\title{
MiR-129-5p is down-regulated and involved in migration and invasion of gastric cancer cells by targeting interleukin-8
}

\author{
Z. JIANG, H. WANG, Y. LI, Z. HOU, N. MA, W. CHEN, Z. ZONG, S. CHEN* \\ Department of Gastrointestinal Surgery, The Sixth Affiliated Hospital of Sun Yat-Sen University, Guangzhou 510655, Guangdong, P.R.China
}

${ }^{*}$ Correspondence: chenshuang1852@126.com

Received January 11, 2016 / Accepted April 25, 2016

\begin{abstract}
Expression of microRNA-129-5p (miR-129-5p) has been reported to decrease in gastric cancer (GC). However, little information is available about how miR-129-5p affects cell migration and invasion of GC. Cancer samples and matched non-tumor adjacent tissues were obtained from patients with GC. Besides, peripheral blood samples were collected from both the patients and healthy volunteers. Expression of miR-129-5p was analyzed by real-time PCR (RT-PCR). After transfection with miR129-5p mimics, miR-129-5p inhibitor, or negative controls in human GC cell line SGC-7901, cell viability, colony-formation ability, migration, and invasion assay were evaluated. Luciferase reporter assay, RT-PCR, and enzyme-linked immunosorbent assay (ELISA) were performed to explore whether interleukin- 8 was a target of miR-129-5p. Further, small interfering RNA (siRNA) against IL-8 was transfected into cells, and then the effects of miR-129-5p inhibitor on migration and invasion were assessed. MiR-129-5p was down-regulated in both GC samples and blood samples compared to their matched non-tumor adjacent tissues and healthy volunteers (both $P<0.05$ ). Compared to the control group, transfection with miR-129-5p inhibitor markedly increased the cell viability, colony-forming ability, and numbers of migrated and invaded cells. Luciferase reporter assay confirmed that IL- 8 was a direct target of miR-129-5p, and IL-8 was negatively regulated by miR-129-5p. Cotransfection of miR-129-5p inhibitor with si-IL-8 reversed the effect of miR-129-5p inhibitor on the migration and invasion of the cells. MiR-129-5p and regulates migration and invasion of GC cells by targeting IL-8.
\end{abstract}

Key words: microRNA-129-5p, gastric cancer, migration and invasion, interleukin-8

Gastric cancer (GC) is the second most frequent lethal cancer worldwide with approximately $50 \%$ cases in China [1]. Most patients who are diagnosed with GC are in advanced stage of disease and predict extremely poor prognosis [2]. The 5 -year survival rate for GC patients varies between 5\% in Stage IV and 90\% in Stage I [3]. Although in recent years tremendous progress has been made in the development and advancement of GC research, the underlying molecular mechanisms involving migration and invasion are still poorly understood.

MicroRNAs (miRNAs) are short noncoding RNAs that are responsible for the regulation of thousands of gene targets by base pairing with the $3^{\prime}$ untranslated region (UTR) [4]. Recently, emerging evidence suggested that miRNAs play significant roles in the initiation, progression, and survival prediction of GC by regulating cell proliferation, invasion, and migration $[5,6]$. MiR-129-5p, one of the mature forms of miR-129-1 and miR-129-2, has been reported to be involved in various neoplastic processes, including GC [7-9]. It has been demonstrated that miR-129-5p serves as an important tumor suppressor, and overexpression of miR-129-5p could significantly decrease the cell proliferation activity of multiple tumor cell lines, such as endometrial tumor cells, lung adenocarcinoma cell lines, bladder cancer cells, and GC cells [7, 10-12]. Another mature form of miR-129-1 and miR-129-2, miR-129-3p, has been suggested as a diagnostic and prognostic biomarker for renal cell carcinoma (RCC), and could regulate cell migration and invasion by downregulating multiple metastasis-related genes [13]. However, little is known about the effect of miR-129-5p on migration and invasion of GC.

Based on previous reports $[7,8,14]$, we investigated the expression pattern of miR-129-5p in GC tissues and peripheral blood samples. In addition, the effect of miR-129-5p on GC cell proliferation, migration, and invasion were explored by altering the endogenous levels of miR-129-5p in human GC cell line SGC-7901 cells. We further investigated the direct targets of miR-129-5p to elucidate the underlying regulatory 
mechanism of migration and invasion in GC. Our study may provide the basis for the development of therapeutic intervention of cancers for GC by decreasing the migration and invasion of the GC cells.

\section{Patients and methods}

Patients and specimens. Between April 2013 and May 2015, 50 patients with GC, including 38 men and 12 women, aged 49-75 years (mean 68 years) underwent radical surgical resection in our hospital were included in this study. The specimens, including GC and their matched non-tumor adjacent tissue samples $(>5 \mathrm{~cm})$, were immediately snapfrozen and stored at $-80^{\circ} \mathrm{C}$. These patients received no local or systemic treatment before the surgery. The diagnosis of GC was confirmed by pathological examination. The tumor size and metastasis status were recorded. In addition, two-milliliter peripheral blood samples were collected from all these patients. Peripheral blood samples from 15 healthy volunteers were used as controls. This study was approved by the local Ethics Committee, and written consents were obtained from all the enrolled patients.

Cell culture. The human GC cell line SGC-7901 was obtained from the Shanghai Institute of Cell Biology at the Chinese Academy of Sciences (Shanghai, PR China). The cells were grown in PRMI 1640 Medium (GIBCO Laboratory, Grand Island, NY) supplemented with 10\% fetal bovine serum (FBS) (Life Technologies), $100 \mathrm{U} / \mathrm{ml}$ penicillin (Life Technologies), and $100 \mu \mathrm{g} / \mathrm{ml}$ streptomycin (Life Technologies) at $37^{\circ} \mathrm{C}$ in a humidified atmosphere of $5 \% \mathrm{CO}_{2}$.

Transfection. MiR-129-5p mimics, miR-129-5p inhibitor, and negative controls were designed and synthesized by Sangon Biotech Co., Ltd. (Shanghai, China). Small interfering RNA (siRNA) against IL-8 and negative control were designed and synthesized by Genepharma Corporation (Shanghai, China). The cells were transfected using Lipofectamine 2000 (Invitrogen, USA) according to the manufacturer's instructions. Briefly, the cells were seeded in a 24-well prior to the transfection. After $24 \mathrm{~h}$ of incubation, the cells were transiently transfected with miR-129-5p mimics (50 nM), miR-129-5p inhibitor (100 nM), or si-IL-8 (100 nM). Forty-eight hours later, the cells were harvested and cell lysates were prepared. The expression levels of miR-129-5p were evaluated by using real-time (RT)-PCR, and the target gene of miR-129-5p IL-8 expression levels were confirmed by RT-PCR and enzymelinked immunosorbent assay (ELISA).

RNA preparation and RT-PCR. MiRNAs were extracted from the tissue samples, peripheral blood samples, or cultured SGC-7901 cells using a miRNA Extraction Kit (Ambion, Carlsbad, CA, USA) according to the manufacturer's instructions. To detect the expression of IL-8, total RNA was extracted from SGC-7901 cells with Trizol reagent (Invitrogen) following the manufacturer's protocols. For analysis of miRNA expression, reverse transcription and stem-loop RT-PCR were carried out using the TaqMan MicroRNA as- says (ABI, Forest City, CA, USA) and subsequently amplified by TaqMan Universal Master Mix II (Life Technologies). U6 snRNA was used as an internal reference. Primers of miR129-5p and U6 were purchased from Genepharma (Shanghai, China). For analysis of mRNA expression, quantitative RTPCR was performed using SYBR green PCR master mix (Qiagen, Germany). Total RNA was reverse-transcribed to complementary DNA (cDNA), amplified and detected by using ABI Prism 7700 system (Applied Biosystems, USA) according to the manufacturer's instructions. GAPDH was employed as an endogenous control for mRNA. The relative expressions of miRNA and mRNA were calculated by using the comparative $2^{-\triangle \Delta C T}$ methods. Each measurement was performed in triplicate.

ELISA. The levels of secreted IL- 8 in the culture supernatants were evaluated by using a commercially available ELISA kits (R\&D Systems) according to the manufacturer's instructions. Absorbance at $450 \mathrm{~nm}$ was measured using a microplate reader (SpectraMAX 340).

Cell viability. After transfection, the cell viability was determined by 3-(4, 5-dimethyl-2-thiazolyl)-2, 5-diphenyl2-H-tetrazolium bromide (MTT) assay in a time-dependent manner. Briefly, SGC-7901 cells were seeded in a 96-well plate before transfection. The cells were cultured for 24, 48, 72 and $96 \mathrm{~h}$. After transfection with miR-129-5p mimics, inhibitors, or negative controls, MTT $(5 \mathrm{mg} / \mathrm{ml}, 20 \mu \mathrm{l})$ was added and incubated for $4 \mathrm{~h}$ at $37^{\circ} \mathrm{C}$. Then dimethyl sulfoxide (DMSO, $150 \mu \mathrm{l})$ was added to remove the supernatant. The optical density (OD) was read at the wavelength of $490 \mathrm{~nm}$ using a Synergy plate reader (BioTek, USA). Assays were done in triplicate.

Cell colony formation. After transfection with miR-129-5p mimics, miR-129-5p inhibitor, si-IL-8 or negative controls, the cells were seeded in 6-well plates at a density of 800 cells per well. The culture medium was changed every three days and allowed to grow for 14 days until visible clones appeared. After washing with phosphate buffer saline (PBS), the cells were fixed with $4 \%$ paraformaldehyde, stained with $0.1 \%$ crystal violet solution, and air dried. The number of colonies was counted under a fluorescence microscope (Zeiss, Germany).

Cell migration and invasion assay. Cell migration and invasion were determined using Transwell migration chambers $(8 \mu \mathrm{m}$ pore size; Becton Dickinson). For the invasion assay, the membranes were coated with a diluted Matrigel (BD Biosciences). After transfection with miR-129-5p mimics, miR-129-5p inhibitor, si-IL-8 or negative controls, the cells $\left(5 \times 10^{4}\right.$ cells/well $)$ were seeded in the upper chambers with serum-free medium. The lower chamber filled with Medium containing 10\% FBS as a chemoattractant. After incubation for $24 \mathrm{~h}$ at $37^{\circ} \mathrm{C}$, non-invaded cells were scraped off with cotton swabs, and the invaded cells were fixed with $4 \%$ paraformaldehyde, stained with $0.5 \%$ toluidine blue and then counted with a light microscopy.

Target prediction. Target genes of miR-129-5p, such as IL-8, were predicted by bioinformatics analysis using Target- 
Scan 6.2 (http://www.targetscan.org) and/or microRNA.org (http: //www. microrna.org).

Luciferase reporter assay. The wild-type (WT) or mutated (Mut) human IL-8 3'-UTR sequence within the predicted target sites was PCR-amplified and linked into the PGM-T vector (Tiangen, Beijing, China) called WT-IL-8 3'UTR and Mut-IL-8 3' UTR, respectively. Plasmid DNA was then isolated and sequenced to confirm reliability. For the reporter assay, HEK-293 cells were transfected with the above constructs $(0.5 \mu \mathrm{g})$ and miR-129-5p mimics $(50 \mathrm{nM})$ or negative controls $(50 \mathrm{nM})$ using the Lipofectamine 2000 reagent (Invitrogen) at 70\%-80\% cell confluence. After $48 \mathrm{~h}$ of transfection, luciferase activity was assessed by using the Dual-luciferase activity assay system (Promega, USA) according to the manufacturer's instructions. Tests were performed in duplicate in three independent samples.

Statistical analysis. Data were expressed as mean \pm standard deviation (SD). Statistical analyses were performed using Statistic Package for Social Science (SPSS, version 19.0, SPSS Inc., Chicago, Illinois, USA) statistical software. Pearson correlation tests were used to determine whether the expression of miR-129-5p was statistically correlated with tumor size. A Pvalue of $<0.05$ was considered to be statistically significant.

\section{Results}

MiR-129-5p was down-regulated in GC samples and blood samples. To evaluate the expression of miR-129-5p in GC, qRT-PCR analysis was performed in 50 pairs of GC tissues and their matched non-tumor adjacent tissues. The results showed that relative expression of miR-129-5p was significantly decreased in cancer tissues compared with the matched non-tumor tissues $(P<0.05)$ (Figure $1 \mathrm{~A})$. Moreover, we evaluated the expression of miR-129-5p in peripheral blood from the patients and 15 healthy volunteers. As indicated in Figure $1 \mathrm{~B}$, we observed that the expression of miR-129-5p in the peripheral blood was also significantly higher in the healthy volunteers than that in the patients with GC $(P<$ $0.05)$. The results demonstrated that miR-129-5p plays an important role in the GC and miR-129-5p might be severed as a biomarker for GC.

MiR-129-5p decreased cell proliferation, migration, and invasion. To assess the functional role of miR-129-5p in GC, we first altered the expression of miR-129-5p by transfection with miR-129-5p mimic or inhibitor. The transfection efficiency was confirmed by qRT-PCR. As expected, the relative expression of miR-129-5p was significantly up-regulated by miR-129-5p mimic but down-regulated by miR-129-5p inhibitor compared with the control group (both $P<0.05$ ) (Figure $2 \mathrm{~A}$ ). After transfection, the cell viability, cell colony formation, migration, and invasion were determined. As indicated in Figure $2 \mathrm{~B}-\mathrm{H}$, compared to the control group, the cell viability, colony-formation ability, and numbers of migrated and invaded cells were all markedly decreased by transfected with miR-129-5p mimic, but obviously elevated by transfected with miR-129-5p inhibitor (all $P<0.05$ ). These results confirmed that miR-129-5p functions as a tumor suppressor gene in GC.

IL-8 was a direct target of miR-129-5p. To predict the target of miR-129-5p, we used two open access programs (TargetScan 6.2 and microRNA.org). IL-8, a pro-inflammatory CXC chemokine, has been reported to promote tumor cell proliferation, survival, and migration and invasion [1518]. Therefore, IL-8 was selected for analysis. As shown in Figure 3 A, IL- 8 was predicted to be a target of miR-129-5p. For the TargetScan 6.2, the parameters were listed as follows: site type (7mer-A1), Context++ score (-0.03), Context++ score percentile (86), Weighted context ++ score $(-0.02)$,
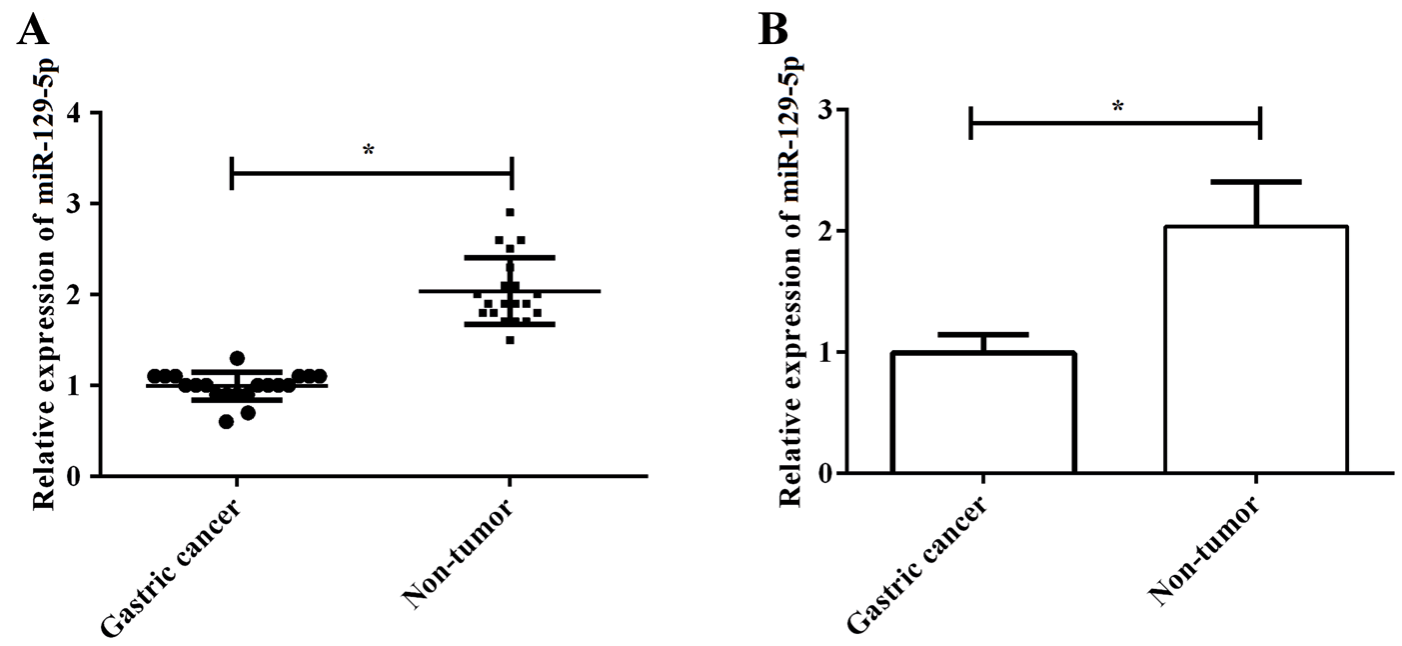

Figure 1. miR-129-5p is significantly decreased in gastric cancer samples and blood samples. A, the relative expression of miR-129-5p in gastric cancer samples; $B$, the relative expression of miR-129-5p in blood samples, ${ }^{*} P<0.05$ compared to non-tumor group. 
A
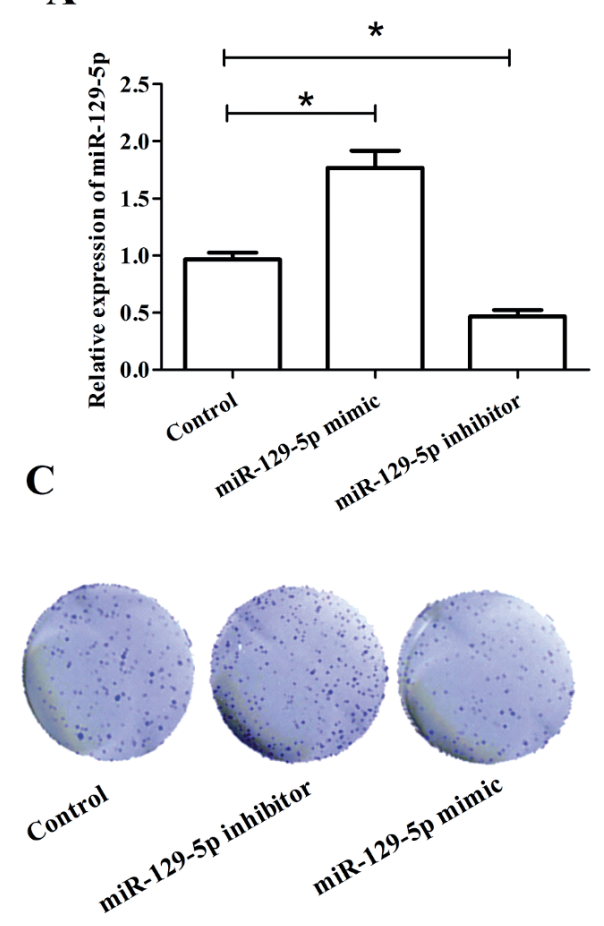

$\mathbf{E}$

\section{G}
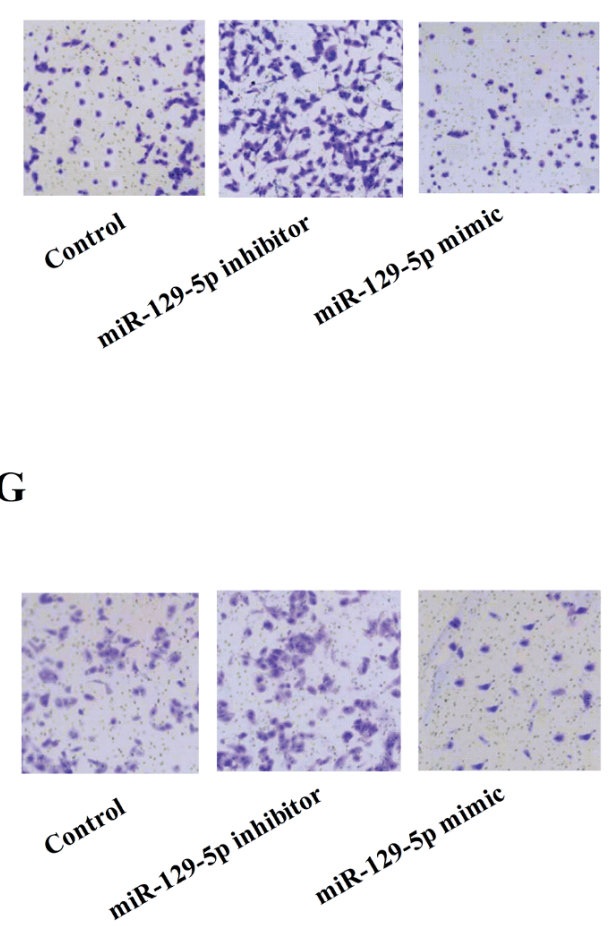

B

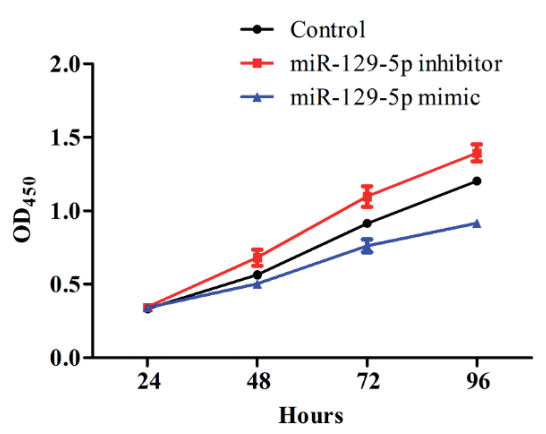

D
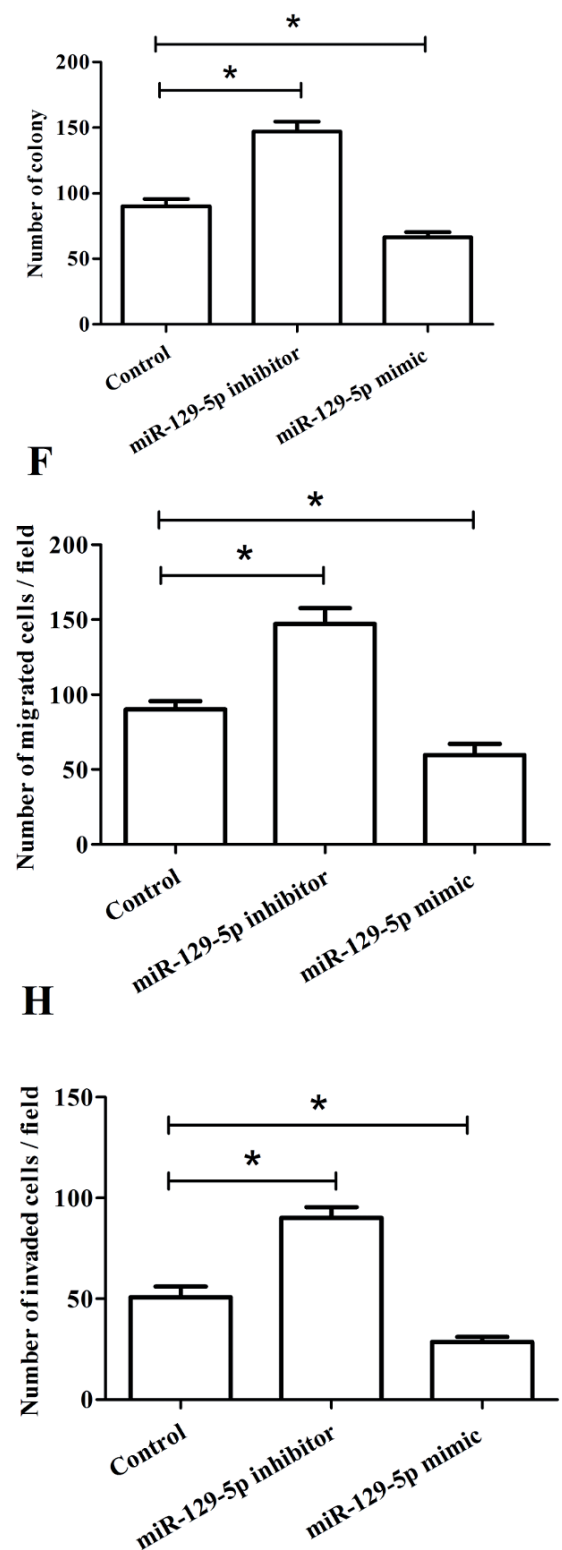

Figure 2. miR-129-5p decreases cell proliferation, cell colony formation, and migration and invasion. A, relative expression of miR-129-5p after transfection with miR-129-5p mimic or inhibitor; $B$, cell viability after transfection; $C$ and $D$, cell colony formation ability after transfection; E and F, number of migrated cells after transfection; $\mathrm{G}$ and $\mathrm{H}$, number of invaded cells after transfection. ${ }^{\star} P<0.05$ compared to the control group 
A

\begin{tabular}{|c|c|c|c|c|c|c|c|}
\hline & $\begin{array}{c}\text { Predicted consequential pairing of target region (top) and } \\
\text { miRNA (bottom) }\end{array}$ & $\begin{array}{l}\text { Site } \\
\text { type }\end{array}$ & $\begin{array}{c}\text { Context++ } \\
\text { score }\end{array}$ & $\begin{array}{c}\text { Context++ score } \\
\text { percentile }\end{array}$ & $\begin{array}{l}\text { Weighted context+1 } \\
\text { score }\end{array}$ & $\begin{array}{c}\text { Conserved branch } \\
\text { length }\end{array}$ & $\mathrm{P}_{\mathrm{CI}}$ \\
\hline $\begin{array}{l}\text { Position 15-21 of IL8 3' UTR } \\
\text { hsa-miR-140-3p.2 }\end{array}$ & 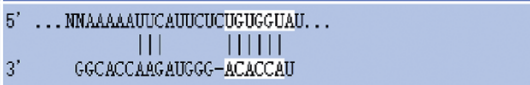 & $\begin{array}{c}7 \mathrm{mer}- \\
\mathrm{A} 1\end{array}$ & -0.18 & 91 & -0.18 & 0.026 & $<0.1$ \\
\hline
\end{tabular}

C hsa-miR-129-5p/IL8 Alignment

\begin{tabular}{|c|c|}
\hline 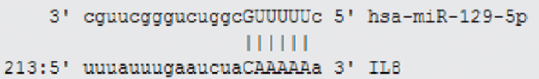 & $\begin{array}{ll}\text { mirSVR score: } & -0.1418 \\
\text { PhastCons score: } & 0.4829\end{array}$ \\
\hline
\end{tabular}

Mouseover a miRNA mature name to see the miRNA/IL8 alignment.

B

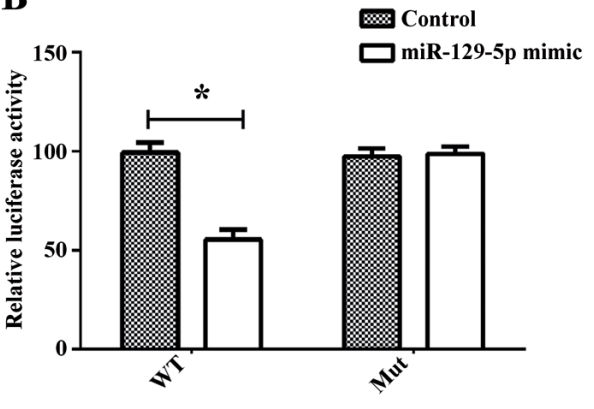

C

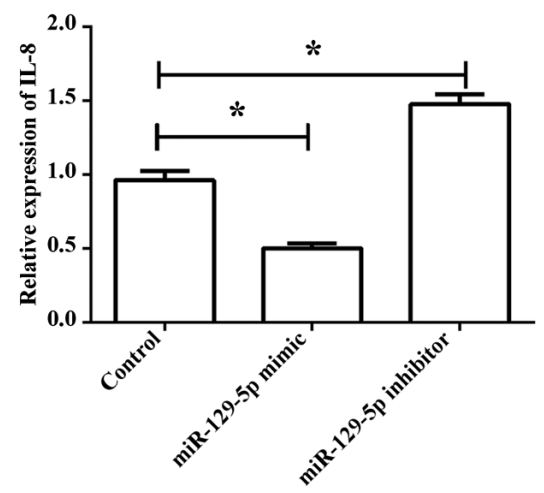

D

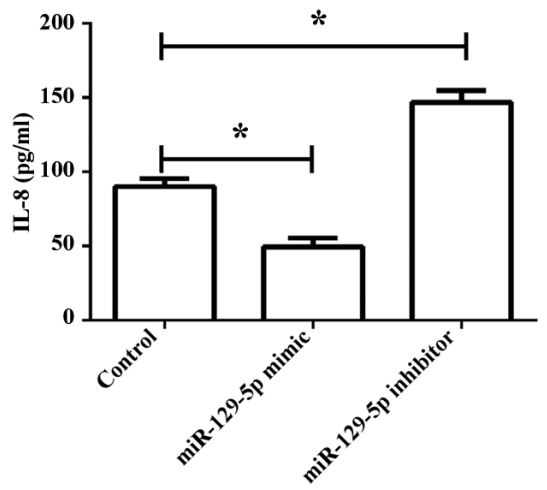

Figure 3. Regulation of IL-8 by miR-129-5p. A, software prediction of miR-129-5p a potential binding sites on IL-8 3'UTR; B, luciferase assays in HEK293 cells with wild-type or mutant IL-8 3'UTR vectors and miR-129-5p mimic or negative control; C, RT-PCR for the relative expression of IL-8 after transfection with miR-129-5p mimic or inhibitor; D, ELISA for the expression of IL-8 after transfection with miR-129-5p mimic or inhibitor. ${ }^{\star} P<0.05$ compared to the control group

Conserved branch length $(0.330)$, and $\mathrm{P}_{\mathrm{CT}}(<0.01)$. For the microRNA.org, the parameters were listed as follows: mirSVR score: -0.1418 and PhastCons score: 0.4829. To validate whether IL-8 was indeed regulated by miR-129$5 \mathrm{p}$ in GC cells, we generated reporter plasmids (WT-IL-8 3'UTR or its mutant form MUT-IL-8 3'UTR). The reporter assay showed that the luciferase activity was significantly decreased by co-transfection of miR-129-5p mimic with WT in SGC-7901 cells compared with the control mimic group, while no significant difference can be seen by co-transfection of miR-129-5p mimic with Mut (Figure 3 B). Transfection of miR-129-5p mimic in SGC-7901 cells significantly decreased both the mRNA and protein levels of IL-8, and while transfection of miR-129-5p inhibitor significantly increased both the mRNA and protein levels of IL- 8 (all $P<0.05$ ) (Figure 3 $\mathrm{C}$ and $\mathrm{D})$. These results suggested that $\mathrm{miR}-129-5 \mathrm{p}$ inhibits IL-8expression.

Inhibition of IL-8 reversed the effect of miR-129-5p inhibitor on migration and invasion. To further confirm the negative relationship between miR-129-5p and target gene IL-8, we determined the effect of miR-129-5p inhibitor on migration and invasion after silencing the expression of
IL-8 in SGC-7901 cells. As shown in Figure 4 A, the expression of IL-8 was significantly decreased by transfection with siRNA targeting IL-8 $(P<0.05)$. The numbers of migrated and invaded cells were statistically down-regulated by cotransfection of miR-129-5p inhibitor with si-IL-8 compared to the cells only transfected by miR-129-5p inhibitor (Figure $4 \mathrm{~B}-\mathrm{E})$. The results suggested that inhibition the expression of IL-8 reversed the effect of miR-129-5p inhibitor on migration and invasion of SGC-7901 cells.

\section{Discussion}

In this study, we focused on the role of miR-129-5p in migration and invasion of human GC cell line SGC-7901 cells, as well as possible regulatory mechanism. Our results demonstrated that the expression of miR-129-5p was significantly lower in GC tissues and peripheral blood samples. Overexpression of miR-129-5p greatly reduced the cell viability, colony-formation ability, migration, and invasion of GC cells. IL-8 was confirmed as a direct target gene of miR-129-5p. MiR-129-5p may function as a new metastasis-related gene in GC by directly regulating the expression of IL- 8 . 
A

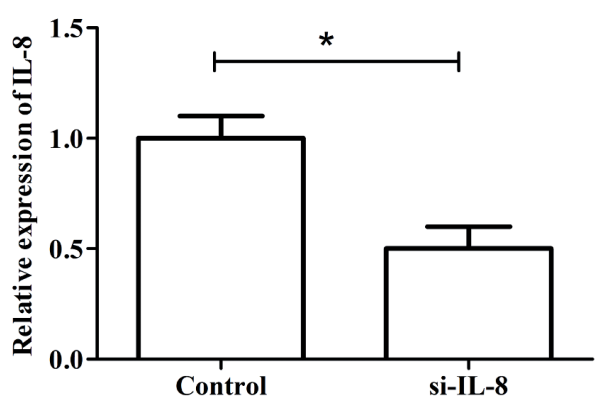

B

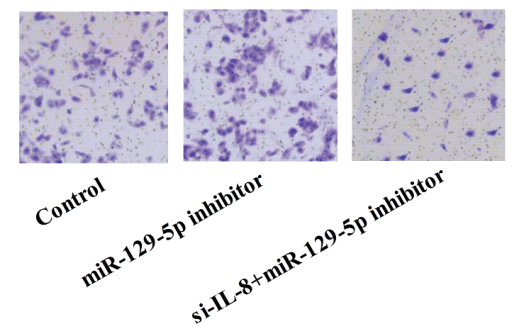

D

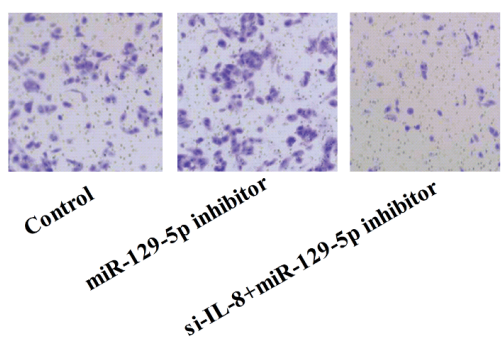

C
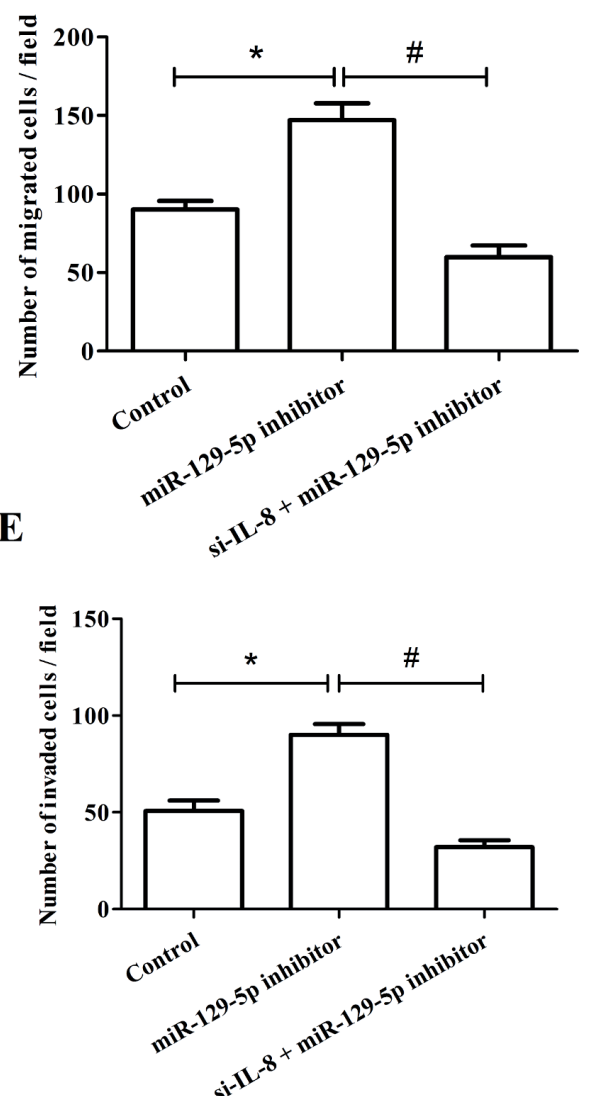

Figure 4 Inhibition of IL-8 reverses the effect of miR-129-5p inhibitor on migration and invasion. A, relative expression of IL-8 after transfection with siRNA against IL-8; B and C, number of migrated cells after transfection; D and E, number of invaded cells after transfection. ${ }^{\star} P<0.05$ compared to the control group; ${ }^{\#} P<0.05$ compared to the miR-129-5p inhibitor group.

A great number of miRNAs have been identified to be expressed at low levels in tumors, acting as oncogenes, antioncogene, or regulators of cancer stem cells and metastasis [19]. Reduced expression of miR-129 has been found in multiple tumor cell lines and in primary tumors, including GC $[7,14,20]$. Yu and co-workers [7] suggested that all miR-129 family members (miR-129-1-3p, miR-129-2$3 p$, and miR-129-5p) showed growth inhibitory in GC by regulating cell proliferation. However, little research has been focused on migration and invasion of miR-129-5p in GC. Therefore, we aimed to clarify the effect of miR-129$5 p$ on GC migration and invasion as well as the underlying mechanisms. First, we evaluated the expression pattern of miR-129-5p in the collected the tumor samples and peripheral blood samples. The data indicated that miR129-5p was down-regulated in both cancer samples and blood samples compared with matched non-tumor adjacent tissues and normal blood samples. Our results were in line 
with previous studies in which miR-129-5p plays critical roles in tumors $[21,22]$. Next, the effect of miR-129-5p on GC cells was explored by assessing the cell viability, colony-formation ability, migration, and invasion ability after altering the expression of miR-129-5p. Our data suggested that miR-129-5p functioned as a tumor suppressor by decreasing cell proliferation, migration, and invasion ability, which was in line with previous study [7].

We further investigated the possible mechanism respect to migration and invasion of miR-129-5p. The capability of cell migration and invasion is regarded as one of the most critical determinant in the process of cancer metastasis, leading to morbidity and mortality. The development of metastasis is an extraordinarily complex and multi-step process that involves in complicated mechanisms $[23,24]$. An emerging body of evidence has suggests that the metastasis can be an early event [25]. It has been estimated that approximately $60 \%$ to $70 \%$ of patients show the metastatic involvement by the time of diagnosis [24]. Therefore, it is imperative to understand the factors that are responsible for tumor dissemination. In the present study, we elucidated the underlying mechanism of miR-129$5 p$ in GC metastasis. Our results indicated that miR-129-5p could directly target the 3'UTR of IL-8 genes, and repressed the post-translational activities. IL-8, known as chemokine (C$\mathrm{X}-\mathrm{C}$ motif) ligand (CXCL) 8, is a pro-inflammatory cytokines that are related to promotion of neutrophil chemotaxis and degranulation. It has well demonstrated that IL-8 is involved in several types of tumor and play significant roles in tumor growth, survival, neovascularization, migration, and invasion [16-18]. Moreover, IL-8 is considered as a target for therapeutic intervention of cancers [26]. Increased serum levels of circulating IL- 8 has been reported in GC patients than healthy controls $[27,28]$, and IL-8 has been suggested to be associated with adhesion, migration, invasion and chemosensitivity, vascularity of GC [29-31]. In addition, previous studies have shown that several miRNAs, such as miR-520b, miR-106a, miR-106b, miR-23a, and miR-93 [32-35], are identified in diverse diseases by targeting IL-8 gene expression. Our results confirmed that IL- 8 was a direct target of miR-129-5p by luciferase reporter assay, and IL- 8 could be negatively regulated by miR-129-5p. To verify miR-129-5p regulates the migration and invasion of GC cells by regulating the expression of IL-8, the expression pattern of IL- 8 was silenced by siRNA, and then the migration and invasion of GC cells were determined after application of miR-129-5p inhibitor. The results showed that silencing the expression of IL-8 reversed the effect of miR-129-5p inhibitor on the migration and invasion of the cells. However, it should be cautiously interpreted due to some limitations in our study. We focused on a GC cell line SGC-7901 only. Second GC cell line or animal research should be performed to confirm the results.

In conclusion, our results indicated that miR-129-5p may serve as a new metastasis-related gene in GC. MiR-129-5p alleviates the migration and invasion of GC cells by suppressing the expression of IL-8.

\section{References}

[[1] FERLAY J, SHIN HR, BRAY F, FORMAN D, MATHERS C et al. Estimates of worldwide burden of cancer in 2008: GLOBOCAN 2008. Int J Cancer 2010; 127: 2893-2917. http://dx.doi. org/10.1002/ijc. 25516

[2] ANG TL, KHOR CJ, GOTODA T. Diagnosis and endoscopic resection of early gastric cancer. Singapore Med J 2010; 51 : 93-100.

[3] YOU W. Gastric cancer screening and early detection. Gastric cancer. Beijing: Chinese Medicine Publishing House 2006; $52-57$.

[4] SIONOV RV. MicroRNAs and Glucocorticoid-Induced Apoptosis in Lymphoid Malignancies. ISRN Hematol 2013; 2013: 348212. http://dx.doi.org/10.1155/2013/348212

[5] LI X, ZHANG Y, ZHANG Y, DING J, WU K et al. Survival prediction of gastric cancer by a seven-microRNA signature. Gut 2010; 59: 579-585. http://dx.doi.org/10.1136/ gut.2008.175497

[6] SONG J, BAI Z, ZHANG Z. MicroRNAs are implicated in the initiation and progression of gastric cancer. Chin Med J (Engl) 2014; 127: 554-559.

[7] YU X, SONG H, XIA T, HAN S, XIAO B et al. Growth inhibitory effects of three miR-129 family members on gastric cancer. Gene 2013; 532: 87-93. http://dx.doi.org/10.1016/j. gene.2013.09.048

[8] YU X, LUO L, WU Y, YU X, LIU Y et al. Gastric juice miR129 as a potential biomarker for screening gastric cancer. Med Oncol 2013; 30: 365. http://dx.doi.org/10.1007/s12032-0120365-y

[9] TSAI KW, WU CW, HU LY, LI SC, LIAO YL et al. Epigenetic regulation of $\mathrm{miR}-34 \mathrm{~b}$ and $\mathrm{miR}-129$ expression in gastric cancer. Int J Cancer 2011; 129: 2600-2610. http://dx.doi. org/10.1002/ijc.25919

[10] HUANG YW, LIU JC, DEATHERAGE DE, LUO J, MUTCH DG et al. Epigenetic repression of microRNA-129-2 leads to overexpression of SOX4 oncogene in endometrial cancer. Cancer Res 2009; 69: 9038-9046. http://dx.doi. org/10.1158/0008-5472.CAN-09-1499

[11] DYRSKJOT L, OSTENFELD MS, BRAMSEN JB, SILAHTAROGLU AN, LAMY P et al. Genomic profiling of microRNAs in bladder cancer: miR-129 is associated with poor outcome and promotes cell death in vitro. Cancer Res 2009; 69: 4851-4860. http://dx.doi.org/10.1158/0008-5472.CAN-08-4043

[12] WU J, QIAN J, LI C, KWOK L, CHENG F et al. miR-129 regulates cell proliferation by downregulating Cdk6 expression. Cell Cycle 2010; 9: 1809-1818. http://dx.doi.org/10.4161/ cc.9.9.11535

[13] CHEN X, RUAN A, WANG X, HAN W, WANG R et al. miR-129-3p, as a diagnostic and prognostic biomarker for renal cell carcinoma, attenuates cell migration and invasion via downregulating multiple metastasis-related genes. J Cancer Res Clin Oncol 2014; 140: 1295-1304. http://dx.doi. org/10.1007/s00432-014-1690-7

[14] XU C, SHAO Y, XIA T, YANG Y, DAI J et al. lncRNAAC130710 targeting by miR-129-5p is upregulated in gastric cancer and associates with poor prognosis. Tumour Biol 
2014; 35: 9701-9706. http://dx.doi.org/10.1007/s13277-014$\underline{2274-5}$

[15] WAUGH DJ, WILSON C. The interleukin-8 pathway in cancer. Clin Cancer Res 2008; 14: 6735-6741. http://dx.doi. org/10.1158/1078-0432.CCR-07-4843

[16] YUAN A, CHEN JJ, YAO PL, YANG PC. The role of interleukin-8 in cancer cells and microenvironment interaction. Front Biosci 2005; 10: 853-865. http://dx.doi. org/10.2741/1579

[17] SCHADENDORF D, MOLLER A, ALGERMISSEN B, WORM M, STICHERLING M ET AL. IL-8 produced by human malignant melanoma cells in vitro is an essential autocrine growth factor. J Immunol 1993; 151: 2667-2675.

[18] VARNEY ML, LI A, DAVE BJ, BUCANA CD, JOHANSSON SL et al. Expression of CXCR1 and CXCR2 receptors in malignant melanoma with different metastatic potential and their role in interleukin-8 (CXCL-8)-mediated modulation of metastatic phenotype. Clin Exp Metastasis 2003; 20: 723 731. http://dx.doi.org/10.1023/B:CLIN.0000006814.48627. $\underline{\mathrm{bd}}$

[19] GEORGE GP, MITTAL RD. MicroRNAs: Potential biomarkers in cancer. Indian J Clin Biochem 2010; 25: 4-14. http:// dx.doi.org/10.1007/s12291-010-0008-Z

[20] SHEN R, PAN S, QI S, LIN X, CHENG S. Epigenetic repression of microRNA-129-2 leads to overexpression of SOX4 in gastric cancer. Biochem Biophys Res Commun 2010; 394: 1047-1052. http://dx.doi.org/10.1016/j.bbrc.2010.03.121

[21] LIU Y, HEI Y, SHU Q, DONG J, GAO Y ET AL. VCP/p97, down-regulated by microRNA-129-5p, could regulate the progression of hepatocellular carcinoma. PLoS One 2012; 7: e35800. http://dx.doi.org/10.1371/journal.pone.0035800

[22] LI M, TIAN L, WANG L, YAO H, ZHANG J ET AL. Downregulation of miR-129-5p inhibits growth and induces apoptosis in laryngeal squamous cell carcinoma by targeting APC. PLoS One 2013; 8: e77829. http://dx.doi.org/10.1371/ journal.pone.0077829

[23] NOLTE F, GIEHL M, HAASS W, NOWAK V, SCHUMANN $\mathrm{C}$ et al. Centrosome aberrations in bone marrow cells from patients with myelodysplastic syndromes correlate with chromosomal instability. Ann Hematol 2013; 92: 1325-1333. http://dx.doi.org/10.1007/s00277-013-1772-7

[24] HUNTER KW, CRAWFORD NP, ALSARRAJ J. Mechanisms of metastasis. Breast Cancer Res 2008; 10 Suppl 1: S2. http:// dx.doi.org/10.1186/bcr1988

[25] SCHMIDT-KITTLER O, RAGG T, DASKALAKIS A, GRANZOW M, AHR A et al. From latent disseminated cells to overt metastasis: genetic analysis of systemic breast cancer progres- sion. Proc Natl Acad Sci U S A 2003; 100: 7737-7742. http:// dx.doi.org/10.1073/pnas.1331931100

[26] FERNANDO RI, CASTILLO MD, LITZINGER M, HAMILTON DH and PALENA C. IL-8 signaling plays a critical role in the epithelial-mesenchymal transition of human carcinoma cells. Cancer Res 2011; 71: 5296-5306. http://dx.doi. org/10.1158/0008-5472.CAN-11-0156

[27] KONNO H, OHTA M, BABA M, SUZUKI S and NAKAMURA S. The role of circulating IL- 8 and VEGF protein in the progression of gastric cancer. Cancer Sci 2003; 94: 735-740. http://dx.doi.org/10.1111/j.1349-7006.2003.tb01511.x

[28] MACRI A, VERSACI A, LODDO S, SCUDERI G, TRAVAGLIANTE $M$ et al. Serum levels of interleukin lbeta, interleukin 8 and tumour necrosis factor alpha as markers of gastric cancer. Biomarkers 2006; 11: 184-193. http://dx.doi. org/10.1080/13547500600565677

[29] KUAI WX, WANG Q, YANG XZ, ZHAO Y, YU R et al. Interleukin-8 associates with adhesion, migration, invasion and chemosensitivity of human gastric cancer cells. World J Gastroenterol 2012; 18: 979-985. http://dx.doi.org/10.3748/ wig.v18.i9.979

[30] JU D, SUN D, XIU L, MENG X, ZHANG C et al. Interleukin-8 is associated with adhesion, migration and invasion in human gastric cancer SCG-7901 cells. Med Oncol 2012; 29: 91-99. http://dx.doi.org/10.1007/s12032-010-9780-0

[31] KITADAI Y, HARUMA K, SUMII K, YAMAMOTO S, UE T ET AL. Expression of interleukin-8 correlates with vascularity in human gastric carcinomas. Am J Pathol 1998; 152: 93-100.

[32] HU N, ZHANG J, CUI W, KONG G, ZHANG S et al. miR$520 \mathrm{~b}$ regulates migration of breast cancer cells by targeting hepatitis B X-interacting protein and interleukin-8. J Biol Chem 2011; 286: 13714-13722. http://dx.doi.org/10.1074/ jbc.M110.204131

[33] QU JQ, YI HM, YE X, LI LN, ZHU JF et al. MiR-23a sensitizes nasopharyngeal carcinoma to irradiation by targeting IL-8/ Stat3 pathway. Oncotarget 2015; 6: 28341-28356. http://dx.doi. org/10.18632/oncotarget. 5117

[34] FABBRI E, BORGATTI M, MONTAGNER G, BIANCHI N, FINOTTI A et al. Expression of microRNA-93 and Interleukin-8 during Pseudomonas aeruginosa-mediated induction of proinflammatory responses. Am J Respir Cell Mol Biol 2014; 50: 1144-1155. http://dx.doi.org/10.1165/ rcmb.2013-01600C

[35] CHUANG TD, LUO X, PANDA H, CHEGINI N. miR-93/106b and their host gene, MCM7, are differentially expressed in leiomyomas and functionally target F3 and IL-8. Mol Endocrinol 2012; 26: 1028-1042. http://dx.doi.org/10.1210/me.2012-1075 